\title{
Production of mycobacterial cell wall glycopeptidolipids requires a member of the MbtH-like protein family
}

Elizabeth Tatham ${ }^{1 \dagger}$, Sivagami sundaram Chavadi ${ }^{1 \dagger}$, Poornima Mohandas ${ }^{1}$, Uthamaphani R Edupuganti ${ }^{1}$, Shiva K Angala ${ }^{2}$, Delphi Chatterjee ${ }^{2}$ and Luis E N Quadri ${ }^{*}$

\begin{abstract}
Background: Glycopeptidolipids (GPLs) are among the major free glycolipid components of the outer membrane of several saprophytic and clinically-relevant Mycobacterium species. The architecture of GPLs is based on a constant tripeptide-amino alcohol core of nonribosomal peptide synthetase origin that is $\mathrm{N}$-acylated with a 3-hydroxy/methoxy acyl chain synthesized by a polyketide synthase and further decorated with variable glycosylation patterns built from methylated and acetylated sugars. GPLs have been implicated in many aspects of mycobacterial biology, thus highlighting the significance of gaining an understanding of their biosynthesis. Our bioinformatics analysis revealed that every GPL biosynthetic gene cluster known to date contains a gene (referred herein to as $\mathrm{g} / \mathrm{H}$ ) encoding a member of the $\mathrm{MbtH}$-like protein family. Herein, we sought to conclusively establish whether gp/H was required for GPL production.
\end{abstract}

Results: Deletion of $g p / H$, a gene clustered with nonribosomal peptide synthetase-encoding genes in the GPL biosynthetic gene cluster of Mycobacterium smegmatis, produced a GPL deficient mutant. Transformation of this mutant with a plasmid expressing gp/H restored GPL production. Complementation was also achieved by plasmid-based constitutive expression of $\mathrm{mbtH}$, a paralog of $\mathrm{g} / \mathrm{H}$ found in the biosynthetic gene cluster for production of the siderophore mycobactin of $\mathrm{M}$. smegmatis. Further characterization of the $\mathrm{gp} / \mathrm{H}$ mutant indicated that it also displayed atypical colony morphology, lack of sliding motility, altered capacity for biofilm formation, and increased drug susceptibility.

Conclusions: Herein, we provide evidence formally establishing that $g p / H$ is essential for GPL production in M. smegmatis. Inactivation of $\mathrm{gp} / \mathrm{H}$ also leads to a pleiotropic phenotype likely to arise from alterations in the cell envelope due to the lack of GPLs. While genes encoding MbtH-like proteins have been shown to be needed for production of siderophores and antibiotics, our study presents the first case of one such gene proven to be required for production of a cell wall component. Furthermore, our results provide the first example of a $\mathrm{mbtH}$-like gene with confirmed functional role in a member of the Mycobacterium genus. Altogether, our findings demonstrate a critical role of $\mathrm{gp} / \mathrm{H}$ in mycobacterial biology and advance our understanding of the genetic requirements for the biosynthesis of an important group of constituents of the mycobacterial outer membrane.

\footnotetext{
* Correspondence: LQuadri@brooklyn.cuny.edu

'Equal contributors

'Department of Biology, Brooklyn College, City University of New York, 2900 Bedford Avenue, Brooklyn, NY 11210, USA

Full list of author information is available at the end of the article
} 


\section{Background}

The cell envelope of members of the Mycobacterium genus contains a unique array of structurally-complex free lipids thought to be non-covalently bound to the mycolic acid layer of the cell wall [1-3]. These free lipids are believed to form a membrane outer leaflet that partners with a mycolic acid-based membrane inner leaflet to form an asymmetric lipid bilayer-like structure. This lipid bilayer constitutes the distinctive outer membrane of the mycobacterial cell envelope. The documented role of some of these free lipids as mycobacterial virulence effectors highlights the enzymes involved in their production as potential target candidates for exploring the development of novel drugs that could assist conventional antimicrobial therapy in the control of mycobacterial infections. Notably, the first inhibitor of the biosynthesis of a group of these free lipids (i.e., phenolic glycolipids [3]) has been recently reported [4]. The inhibitor works in a manner analogous to that of the first reported inhibitor of siderophore (iron chelator) biosynthesis [5,6], and it blocks the production of phenolic glycolipids in Mycobacterium tuberculosis and other mycobacterial pathogens [4].

Glycopeptidolipids (GPLs) are among the major free glycolipid components of the outer membrane of several Mycobacterium species [7,8] (Figure 1). The GPLproducing species include saprophytic mycobacteria, such as Mycobacterium smegmatis (Ms), and many clinicallyrelevant nontuberculous mycobacteria. The members of the Mycobacterium avium-Mycobacterium intracellulare complex (MAC) are among the GPL producers of clinical significance. MAC infections cause pulmonary and extrapulmonary diseases in both immunocompromised and immunocompetent individuals $[9,10]$. Importantly, GPLs have been implicated in many aspects of mycobacterial biology, including host-pathogen interaction [11-17], sliding motility $[18,19]$, and biofilm formation $[18,20]$. An altered expression profile of GPLs has been observed in drug-resistant clinical isolates of MAC [21], a finding that raises the possibility that GPL production might have an impact on drug susceptibility as well. Thus, elucidation of the GPL biosynthetic pathway is important not only because it will expand our understanding of cell wall biosynthesis in mycobacteria, but it may also illuminate potential routes to alternative therapeutic strategies against infections by MAC and other opportunistic mycobacterial human pathogens.

Structures of GPLs from several mycobacteria have been characterized (reviewed in references $[7,8]$ ). In brief, GPL molecules are composed of an $\mathrm{N}$-acylated lipopeptide core decorated by a variable pattern of glycosylation that is built from $\mathrm{O}$-methylated and $\mathrm{O}$-acetylated sugar units. The peptide moiety is the tripeptideamino alcohol D-phenylalanine-D-allothreonine-Dalanine-L-alaninol (D-Phe-D-alloThr-D-Ala-L-alaninol). This tripeptide-amino alcohol is assembled by nonribosomal peptide synthetases (NRPSs) designated Mps1 and Mps2 in Ms [22-25], whereas biosynthesis of the lipid substituent (3-hydroxy/methoxy C28-C35 acyl chain) is believed to require a dedicated polyketide synthase (PKS) [24]. NRPSs and PKSs are two large families of enzymes that are best known for their involvement in the synthesis of natural products with pharmacological activities of clinical significance $[26,27]$ and microbial siderophores [28,29]. $N$-acylation of the tripeptide-amino alcohol of Ms GPLs has been proposed to require the protein PapA3 [24], a member of the polyketide-associated protein (Pap) family of acyltransferases [30,31]. Lastly, various glycosyltransferases, methyltransferases and acetyltransferases have been implicated or are suspected to be involved in the building of the glycosyl portion of GPLs $[7,8,24,32]$.

Despite the increasingly recognized widespread presence of GPLs in mycobacteria and the relevance of these compounds in MAC and other mycobacteria of clinical significance, the GPL biosynthetic pathway remains incompletely understood. The individual involvement of several genes suspected to be required for GPL production remains to be experimentally probed. In particular, the involvement of a gene encoding a member of the MbtH-like protein family (NCBI CDD pfam 03621) $[33,34]$ and clustered with the NRPS-encoding genes required for D-Phe-D-alloThr-D-Ala-L-alaninol assembly in GPL production has been hypothesized [23-25,35], but not conclusively demonstrated. MbtH-like proteins form a family of small proteins (60-80 amino acids) linked to secondary metabolite production pathways involving NRPSs [34]. The founding member of this protein family is $\mathrm{MbtH}$, a protein encoded in the mycobactin siderophore biosynthetic gene cluster of $M$. tuberculosis [33].

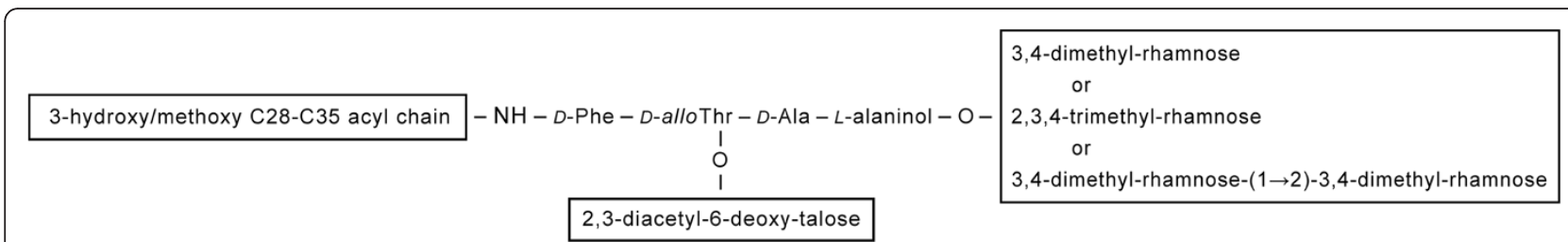

Figure 1 Representative structures of glycopeptidolipids. The depicted GPLs correspond to those found in Mycobacterium smegmatis. 
Recent seminal biochemical studies have established that $\mathrm{MbtH}$-like proteins activate amino acid adenylation domains of NRPSs [36-40]. Genes encoding MbtH-like proteins have been shown to be required for production of siderophores or antibiotics by mutational analysis [41-44]. Interestingly, however, we have recently shown by mutational analysis that the $\mathrm{mbtH}$ orthologue in the mycobactin biosynthetic gene cluster of $M s$ (MSMEG_4508) is not essential for mycobactin production [35]. Similarly, the $m b t H$-like gene in the biosynthetic gene cluster of the balhimycin glycopeptide antibiotic has been shown not to be required for antibiotic production [45]. These findings illustrate the well-recognized limitations of bioinformatics-based genetic predictions in complex biosynthetic pathways and highlight the need for probing gene involvement by unconfounded mutational analysis. In this study, we provide evidence unequivocally establishing that the conserved $m b t H$-like gene (herein referred to as $g p l H$ ) located in the GPL biosynthetic gene locus of $M s$ is essential for GPL production. This finding presents the first case of a $m b t H$-like gene required for biosynthesis of a cell wall component and provides the first example of a $\mathrm{mbtH}$-like gene with confirmed functional role in a member of the Mycobacterium genus. Moreover, we show that loss of gplH leads to a mutant with atypical colony morphology, lack of sliding motility, reduced biofilm formation capacity, and increased antimicrobial drug susceptibility. Altogether, this study demonstrates a critical role for $g p l H$ in mycobacterial biology and advances our understanding of the genetic requirements for the biosynthesis of an important group of constituents of the unique mycobacterial outer membrane.

\section{Results and discussion}

\section{Conservation of a MbtH homologue in the GPL biosynthetic pathway}

$\mathrm{MbtH}$ is a protein encoded in the mycobactin siderophore biosynthetic gene cluster of $M$. tuberculosis and the founding member of the $\mathrm{MbtH}$-like protein family (NCBI CDD pfam 03621) [33]. Our analysis of available genome sequences of GPL producers revealed that every GPL biosynthetic gene cluster known to date contains a $m b t H$-like gene located upstream of NRPS-encoding genes required for D-Phe-D-alloThr-D-Ala-L-alaninol assembly (Figure 2). The MbtH-like protein orthologues encoded by these $\mathrm{mbtH}$-like genes are comprised of 6993 amino acids and have remarkable sequence identity (80-100\%) (Figure 3). This sequence identity extends to the three fully conserved tryptophan residues that are a hallmark of the protein family (NCBI CDD pfam 03621) [33] (Figure 3A). The open reading frame corresponding to the $m b t H$-like gene of $M$. avium 2151 (Figure 2) has not been previously annotated; however, our genome sequence analysis revealed its presence. The MbtH-like protein encoded by this gene is shown in the protein alignment (Figure 3A). The orthologous $m b t H$-like genes or $\mathrm{MbtH}$-like proteins in the other species shown in Figure 2 have been annotated each as $m b t H$ or $\mathrm{MbtH}$, respectively $[24,46]$, presumably due to their sequence relatedness with $M$. tuberculosis $\mathrm{MbtH}$. This name assignment is misleading as these genes are not orthologues of $m b t H$, the gene of the mycobactin biosynthetic pathway present in many mycobacteria, including $M$. smegmatis, M. abscessus, and M. avium [33,35]. This name assignment leads to gene nomenclature confusion by resulting in more than one gene named $m b t H$ in the same species. We proposed herein to name all the orthologous $m b t H$-like genes associated with GPL production as $g p l H$, a name derived from glycopeptidolipid and $m b t \underline{H}$ and not previously assigned to any mycobacterial gene.

\section{Deletion of $g p / H$ in $M$. smegmatis}

Our bioinformatics analysis revealed that every GPL biosynthetic gene cluster known to date contains a $m b t H$ like gene, $g p l H$. The involvement of this conserved gene in GPL production remains unproven. Herein, we sought to conclusively establish whether $g p l H$ was required for GPL production. To this end, we engineered $M s \Delta g p l H$, a mutant with an unmarked, in-frame deletion of $g p l H$ (Figure 4A), the $M s$ gene upstream of the NRPSencoding gene mps1 (Figure 2), and assessed the ability of this mutant to produce GPLs as described below. Ms was selected as a representative prototype of GPL producers for the studies presented herein due to its superior experimental tractability compared with other GPL producers (e.g., MAC members).

The $g p l H$ deletion was engineered using the $g p l H$ deletion cassette-delivery suicide vector p2NIL-GOALc$\Delta \mathrm{gplH} \quad \mathrm{c}(\sim 16 \mathrm{~kb}$, Figure $4 \mathrm{~B})$ in a homologous recombination- and counter selection-based approach that replaced $g p l H$ by a 17 -codon gene remnant cloned into the vector. The deletion in $M s \Delta g p l H$ encompassed 59 central amino acids of the predicted MbtH-like protein encoded by gplH (GplH, MSMEG_0399; 76 amino acids, Figure 3A). The deletion was verified by PCR using primer pairs that produced amplicons of different sizes depending on whether the genomic DNA used as PCR template was wild type (WT) or carried the gene deletion (Figure 4C). The successful engineering of $M s$ $\triangle g p l H$ set the stage for probing the involvement of $g p l H$ in GPL production.

\section{The gene $g p / H$ is essential for GPL production}

We investigated the effect of the $g p l H$ deletion in $M s$ $\Delta g p l H$ on GPL production using TLC and MS analyses. In addition, a control strain for genetic complementation analysis was constructed $(M s \Delta g p l H+\mathrm{pCPO}-g p l H)$, and 


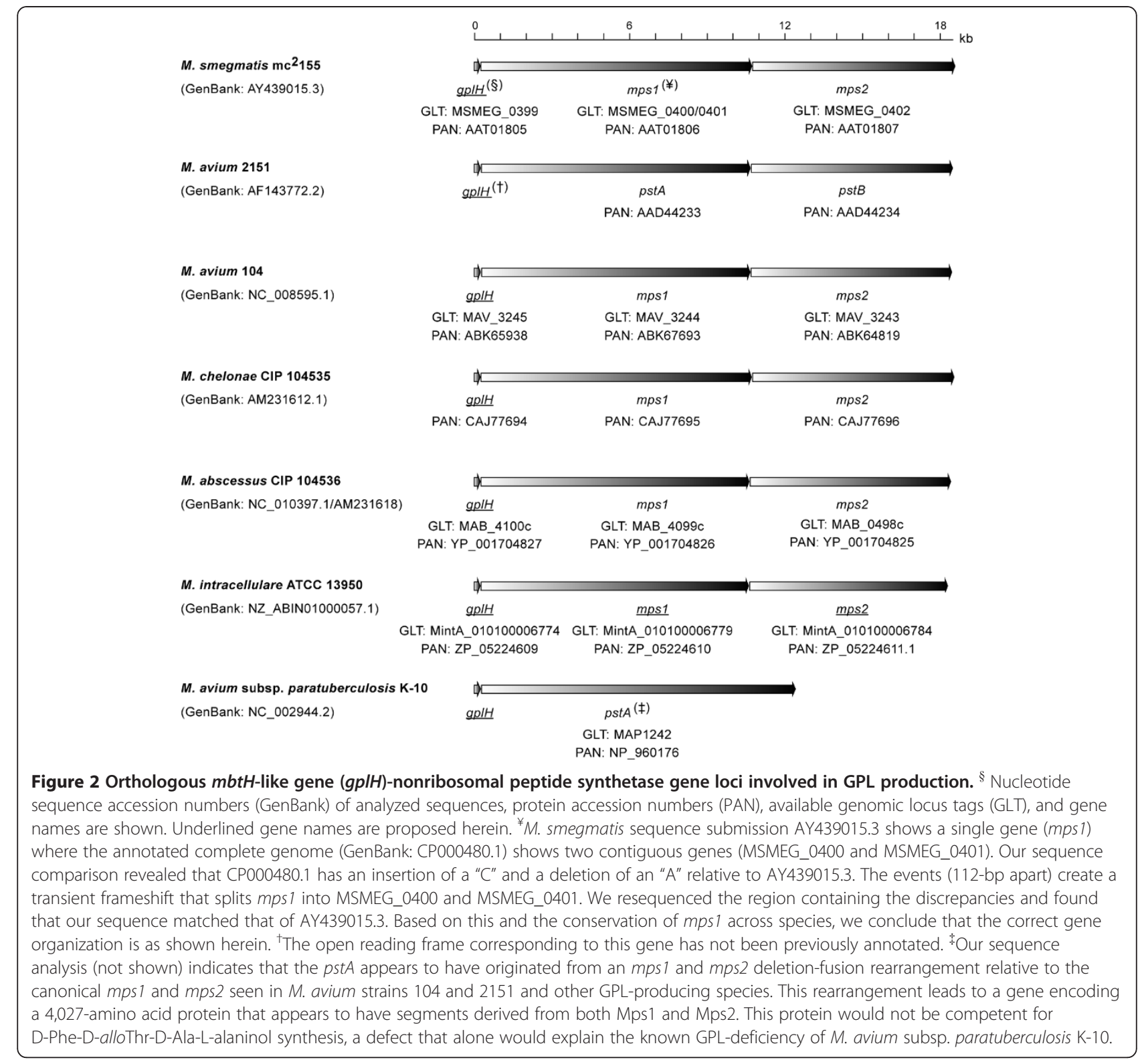

the ability of this strain and that of $M s$ WT controls to produce GPLs was investigated. Representative results from the TLC analysis are shown in Figure 5. The analysis of lipid extracts from the parental $M s$ WT strain, or $M s$ WT bearing the empty $\mathrm{pCPO}$ vector, revealed the expected production of GPLs in these WT controls. Conversely, analysis of lipid extracts from $M s \Delta g p l H$ did not reveal detectable amounts of GPLs. Transformation of $M s \Delta g p l H$ with pCP0-gplH (a pCP0-based plasmid expressing $g p l H)$ rendered the strain $M s \Delta g p l H+$ pCPO$g p l H$, for which TLC analysis demonstrated that production of GPLs was restored to levels comparable to those seen in the WT controls. In contrast, $M s \Delta g p l H$ retained its GPL deficient phenotype after transformation with empty pCP0 vector (strain $M s \Delta g p l H+\mathrm{pCPO}$ ). The results of our complementation analysis rule out the possibility that the GPL deficient phenotype observed in $M s \Delta g p l H$ is due to a polar effect of the $g p l H$ deletion on downstream genes required for GPL production (i.e., mps1 and mps2; Figure 2).

The presence of GPLs was probed for in lipid samples from $M s \mathrm{WT}+\mathrm{pCP} 0, \quad M s \Delta g p l H+\mathrm{pCP}$, and $M s$ $\Delta g p l H+\mathrm{pCP} 0-g p l H$ (complemented strain) by GC-MS analysis as well. The pCP0-bearing strains, $M s \mathrm{WT}+$ $\mathrm{pCPO}$ and $M s \Delta g p l H+\mathrm{pCPO}$, rather than their respective plasmid-free parental strains, were used in these experiments so that the WT, the mutant, and the complemented strain could all be cultured under identical conditions (i.e., kanamycin-containing growth medium) for comparative analysis by GC-MS. Representative 


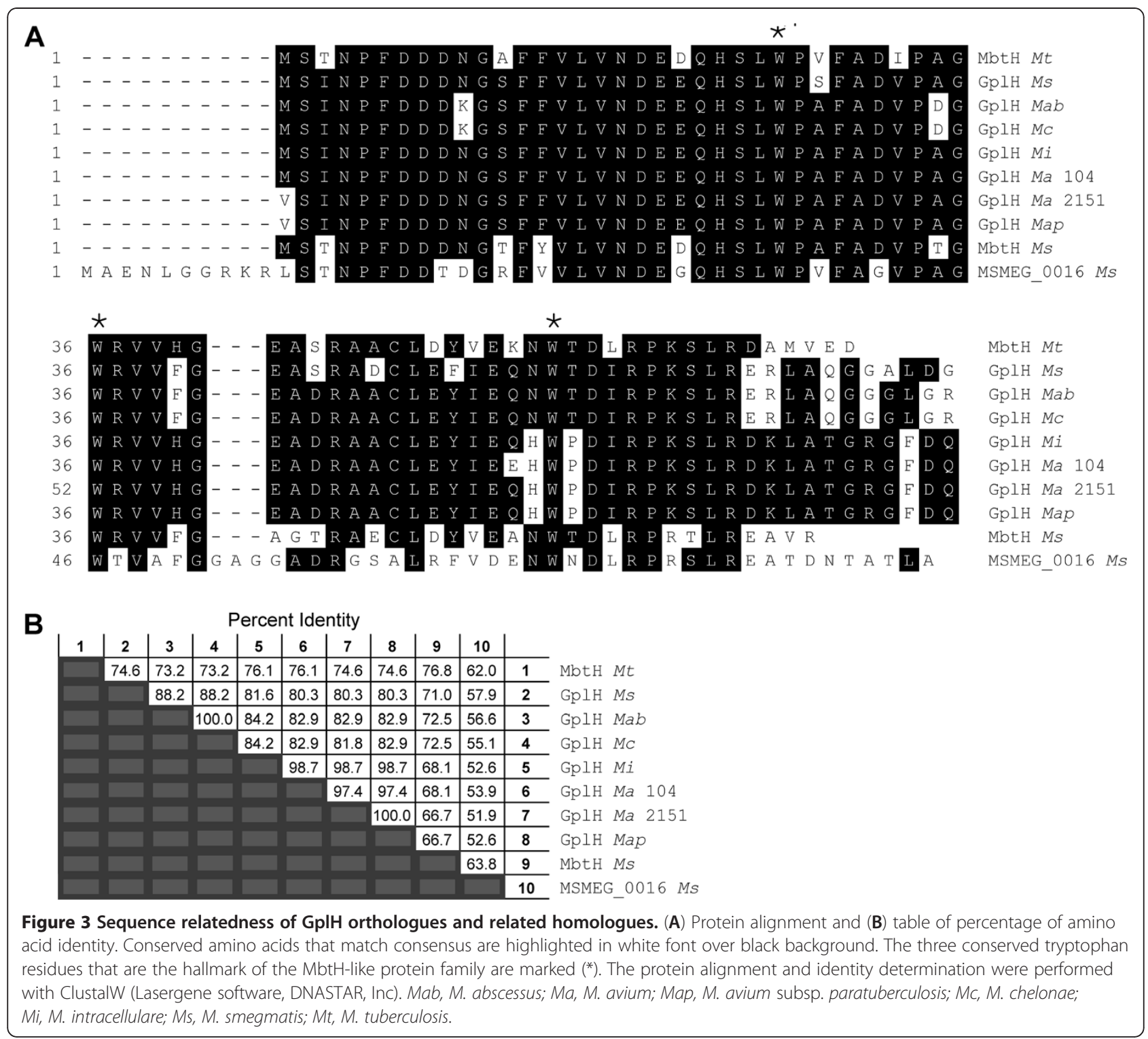

results from the GC-MS analysis are shown in Figure 6. This analysis probed for the presence of the alditol acetate derivatives of the characteristic glycosyl residues of Ms GPLs as a fingerprint indicator of the presence of GPLs in the lipid samples analyzed [47]. The GC-MS analysis of samples from $M s \mathrm{WT}+\mathrm{pCP0}$ revealed the expected $\mathrm{m} / \mathrm{z}$ peak array consistent with the characteristic presence of alditol acetate derivatives of the 2,3,4-trimethyl-rhamnose, 3,4-dimethyl-rhamnose and 6deoxy-talose components of GPLs [7,8,47]. Conversely, these alditol acetate derivatives were not detected by GC-MS analysis of samples from $M s \Delta g p l H+$ pCPO. The samples from the complemented strain, Ms $\Delta g p l H+$ pCP0-gplH, displayed an $\mathrm{m} / z$ peak array comparable to that of Ms WT + pCP0 and consistent with the presence of the alditol acetate derivatives originating from GPLs (not shown). Overall, the results of the GC-MS analysis and the results of the TLC analysis are in agreement with each other and, coupled with our genetic complementation-controlled analysis, conclusively demonstrate that $g p l H$ is essential for production of GPLs.

Based on the recent elucidation of the function of $\mathrm{MbtH}$-like proteins as amino acid adenylation domain activators [36-40], it is reasonable to propose that $\mathrm{GplH}$ is required for the assembly of the D-Phe-D-alloThr-DAla-L-alaninol core moiety of GPLs by the Mps1-Mps2 NRPS system. GplH might act as a critical activator of the amino acid adenylation activity of one or more of the four amino acid adenylation domains predicted by sequence analysis of the Mps1-Mps2 NRPS system $[22,23]$. Biochemical studies will be required to investigate this possibility. 
A

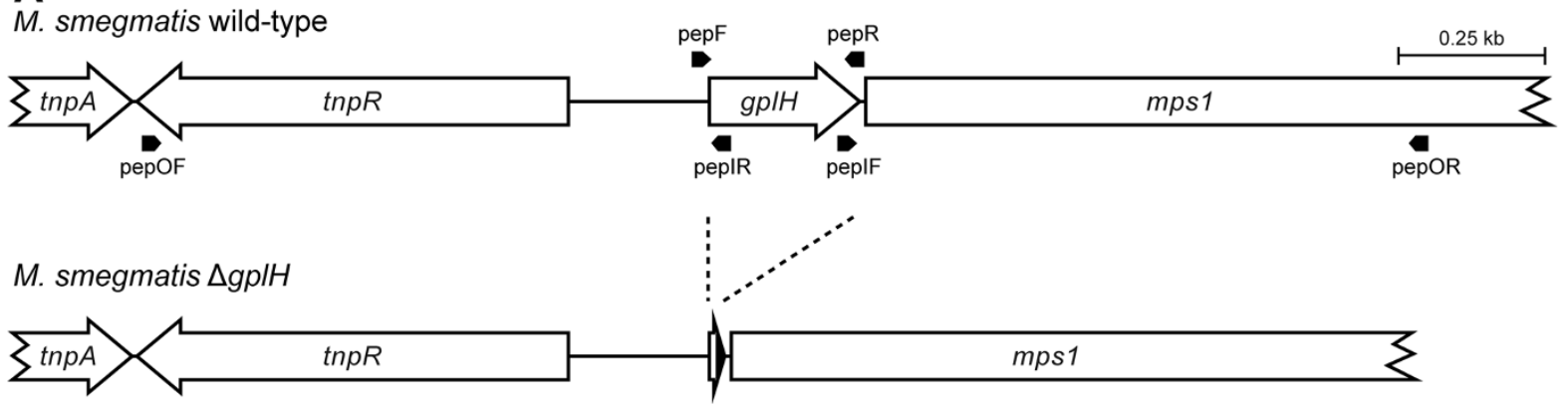

B

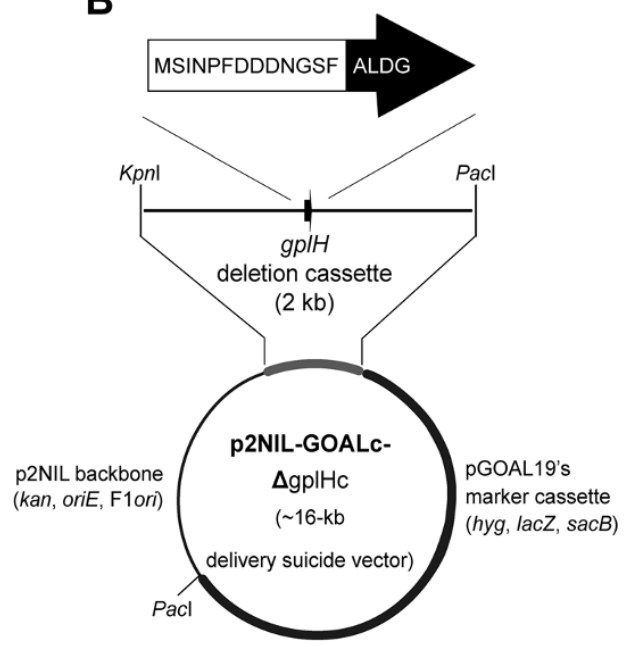

C

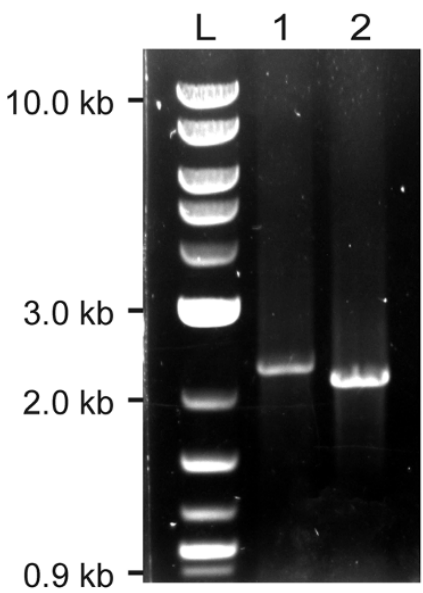

L $\quad 3 \quad 4$

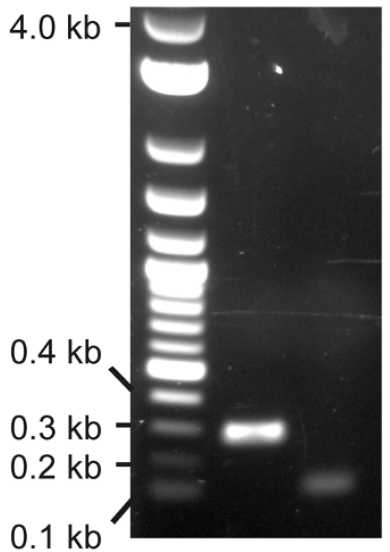

Figure 4 Construction of $\boldsymbol{M}$. smegmatis $\Delta \mathbf{g p l H}$. (A) Scheme illustrating the deletion in the chromosome of Ms $\Delta g p / H$. The position of each primer used in this study is shown. (B) Scheme of the $g p / H$ deletion cassette-delivery suicide vector used for construction of Ms $\Delta g p / H$. The $g p / H$ deletion leaves behind a gene remnant coding for only the first 13 (black print) and last 4 (white print) amino acids of GplH. This gene remnant in $\Delta \mathrm{gplHc}$ is flanked by $\sim 1 \mathrm{~kb}$ of downstream and upstream WT sequence for homologous recombination with the chromosome. (C) Agarose gel electrophoresis showing PCR-based confirmation of the gp/H deletion in Ms $\triangle$ gp/H. Lanes: 1, Ms WT (2,239-bp amplicon expected with primers pepOF and pepOR); 2, Ms $\Delta$ gp IH (2,068-bp amplicon expected with primers pepOF and pepOR); 3, Ms WT (278-bp amplicon expected with primers pepF and pepR); 4, Ms $\Delta g p / H$ (101-bp amplicon expected with primers pepF and pepR); L, DNA ladder marker.

\section{MbtH-mediated cross-talk between GPL biosynthesis and mycobactin biosynthesis}

We noted that $M s$ has two potential $m b t H$-like genes located outside the GPL biosynthetic gene cluster. One of these genes is the $m b t H$ orthologue in the mycobactin biosynthetic gene cluster of $M s$ mentioned above [35]. The second gene, MSMEG_0016, is clustered with genes implicated in the production of the siderophore exochelin [48-50]. The protein products of these two $\mathrm{Ms} \mathrm{gplH}$ paralogues have considerable amino acid sequence identity between themselves and with $\mathrm{GplH}$ and $M$. tuberculosis $\mathrm{MbtH}$ (Figure 3B). The GPL deficiency of $M s$ $\Delta g p l H$ indicates that neither of these two $M s g p l H$ paralogues can support the production of GPLs in $M s \Delta g p l H$ to a meaningful level under our culturing conditions.

It is worth noting that $\mathrm{Ms} \mathrm{mbtH}$ and MSMEG_0016 are associated with siderophore production pathways known to be repressed during growth under iron-rich conditions [51,52]. This fact raises the possibility that neither of these genes is expressed (or they are poorly expressed) in the iron-rich standard Middlebrook media used in our studies. With this consideration in mind, we explored whether an increase in expression of $\mathrm{Ms} m b t H$ (encoding the paralogue with the higher homology to GplH, Figure 3) could complement the GPL deficiency of $M s \Delta g p l H$. To this end, we evaluated GPL production in $M s \triangle g p l H$ after transformation of the mutant with pCP0-mbtHMs (expressing $M s m b t H$ ). TLC analysis of lipid extracts from the transformant revealed the presence of GPLs, thus indicating that plasmid-directed constitutive expression of $M s \mathrm{mbtH}$ complements the GPL deficient phenotype of $M s \Delta g p l H$ (Figure 5). Thus, it appears that $M s \mathrm{MbtH}$ has the potential to functionally replace $\mathrm{GplH}$ if present in sufficient quantities. This 


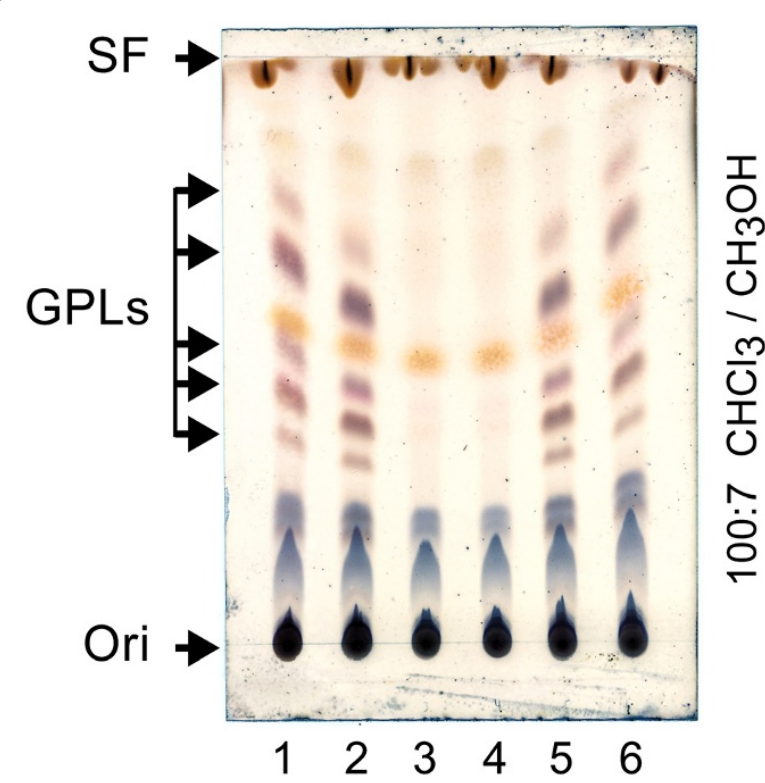

Figure 5 Deletion of $g p / H$ leads to GPL deficiency.

Representative TLC analysis of lipid samples from: Ms WT; 2 , Ms WT + pCPO; 3, Ms $\Delta g p / H ; 4$, Ms $\Delta g p / H+p C P 0 ; 5, M s \Delta g p / H+p C P 0-$ gplH; and 6, Ms $\triangle g p / H+p C P 0-m b t H M s$. The TLC solvent system is indicated. Ori, origin; SF, solvent front.

cross-complementation phenomenon is in line with recent cell-based studies demonstrating MbtH-like protein-mediated cross-talk between NRPS systems $[41,44]$. Our finding is also consistent with reported in vitro enzymology indicating that, at least in some cases, the activity of amino acid adenylation domains of NRPSs can be stimulated not only by bona fide MbtH-like protein partners, but also by MbtH-like protein homologues from disparate natural product biosynthetic pathways $[39,40]$.

\section{Deletion of $g p / H$ leads to a pleiotropic phenotype}

Colony morphotype, biofilm formation and sliding motility are properties that have been shown to be altered in GPL deficient mutants [18-20,23]. Loss of GPL also perturbs bacterial surface properties [19,32] and reduces the cell-wall permeability barrier to chenodeoxycholate uptake [19]. Interestingly, an altered profile of GPLs has been observed in drug-resistant MAC isolates [21]. This finding raises the possibility that GPL production might have an impact on antimicrobial drug susceptibility as well. We investigated whether deletion of $g p l H$ had an effect on all these properties. Ms WT + pCPO and $M s$ $\Delta g p l H+\mathrm{pCP} 0$, rather than their respective plasmid-free parental strains, were used in the experiments so that the WT, the mutant, and the complemented Ms $\Delta g p l H+$ pCP0-gplH strain could all be cultured under identical conditions (i.e., kanamycin-containing growth media) for comparative analysis. Representative results from these studies are shown in Figure 7.
Ms is known to develop into smooth, reddish colonies with a glossy and translucent appearance when grown on low carbon source congo red agar plates [23]. As expected, $M s \mathrm{WT}+\mathrm{pCP0}$ displayed this characteristic morphotype in our congo red agar plate assay (Figure 7A). Ms $\triangle g p l H+\mathrm{pCPO}$, however, had a drastically different morphotype. The mutant was characterized by rough, whitish colonies with a non-translucent and dried appearance. The strain $M s \Delta g p l H+\mathrm{pCP} 0-g p l H$ had a morphotype more similar to WT than to that of the mutant, indicating partial complementation by episomal expression of $g p l H$ in the congo red agar assay. Deletion of $g p l H$ also altered the ability of $M s$ to form biofilms (Figure 7B). Ms WT $+\mathrm{pCP0}$ formed a continuous, thin biofilm at the liquid-air interface, as expected based on previous reports [53,54]. In contrast, $M s \Delta g p l H+\mathrm{pCP0}$ failed to develop such a biofilm and instead grew as chunky patches on the liquid surface. The strain $M s$ $\Delta g p l H+\mathrm{pCP} 0-g p l H$ produced biofilms comparable to those seen with $M s \mathrm{WT}+\mathrm{pCP}$. Sliding motility was also compromised in $M s \Delta g p l H+\mathrm{pCP0}$ (Figure 7C). The mutant did not show sliding motility, whereas $M s \mathrm{WT}+$ pCP0 was highly active in the motility assay. $M s \Delta g p l H+$ pCP0-gplH also displayed sliding motility, although the motility was somewhat reduced compared to WT. This observation indicates partial complementation by episomal expression of $g p l H$. Overall, these results clearly indicate that deletion of $g p l H$ has a profound impact on colony morphotype, biofilm formation, and sliding motility. These mutant phenotypes have previously been associated with other GPL deficient strains and attributed to alterations of the properties of the cell surface due to lack of GPLs. Thus, it is likely that the phenotypes observed in the $g p l H$ mutant arise from its GPL deficiency.

In contrast to the drastic impact of the $g p l H$ deletion on colony morphotype, biofilm formation and sliding motility, lack of $g p l H$ had a relatively minor effect on antimicrobial drug susceptibility. When compared with $M s \mathrm{WT}+\mathrm{pCP} 0$ (control strain), Ms $\Delta g p l H+\mathrm{pCP0}$ showed a slight, yet consistent, increase in susceptibility to only two drugs (cefuroxime and cefotaxime) from a panel of 15 drugs of different classes tested in standard disk diffusion assays.

Interestingly, these two drugs belong to the cephalosporin class, suggesting that the hypersusceptibility of the mutant is antibiotic-class dependent. Representative results illustrating the hypersusceptibility of the mutant to these cephalosporins are shown in Figure 7D.

Streptomycin susceptibility results are also shown in Figure 7D. The streptomycin susceptibility is presented as an example of those drugs to which the mutant had no meaningful difference in susceptibility relative to the WT control. The $M s \Delta g p l H+\mathrm{pCP0}-g p l H$ strain showed a drug susceptibility pattern similar to that of $M s$ WT + $\mathrm{pCP}$, indicating that the hypersusceptible phenotype of 


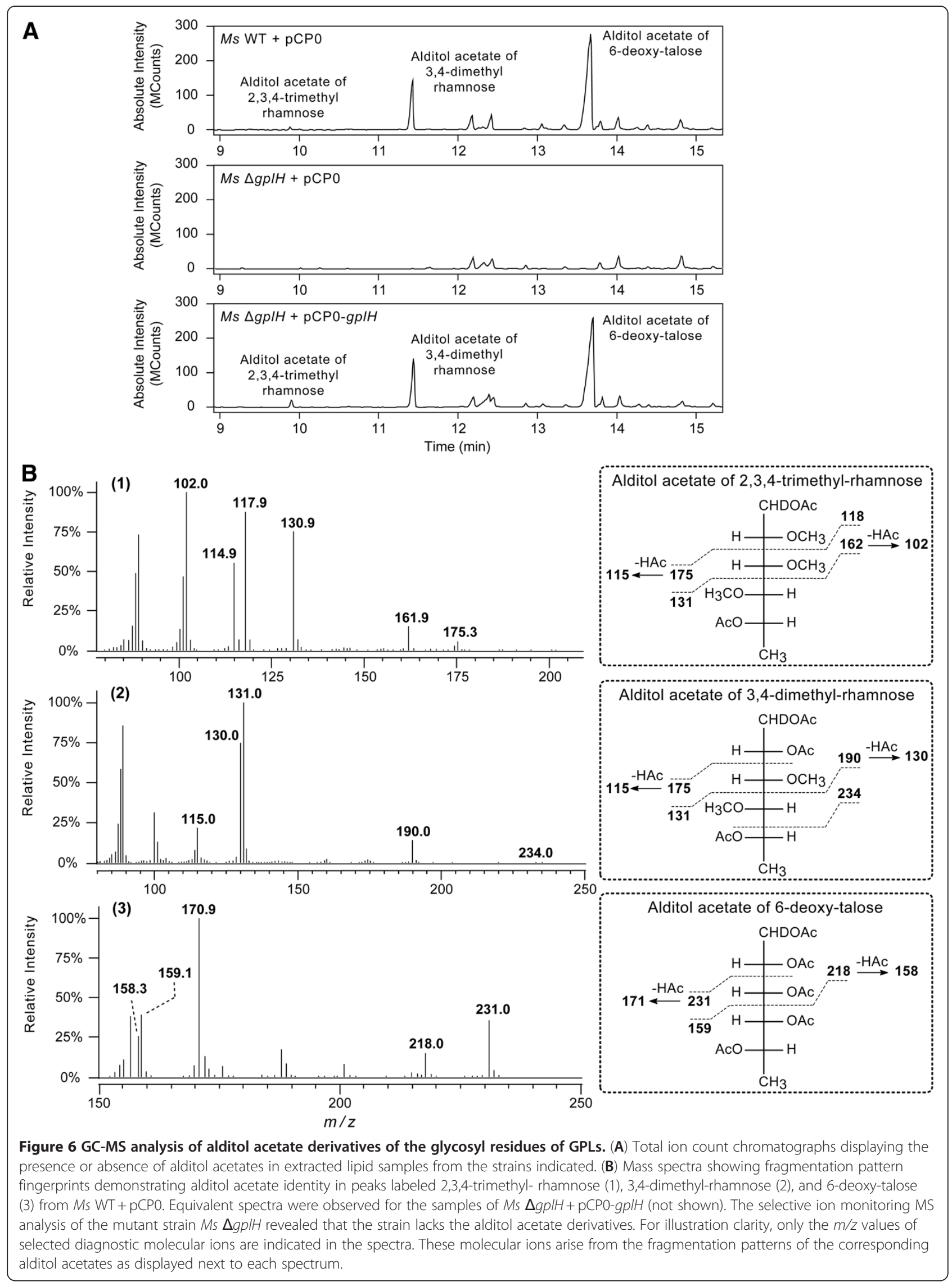




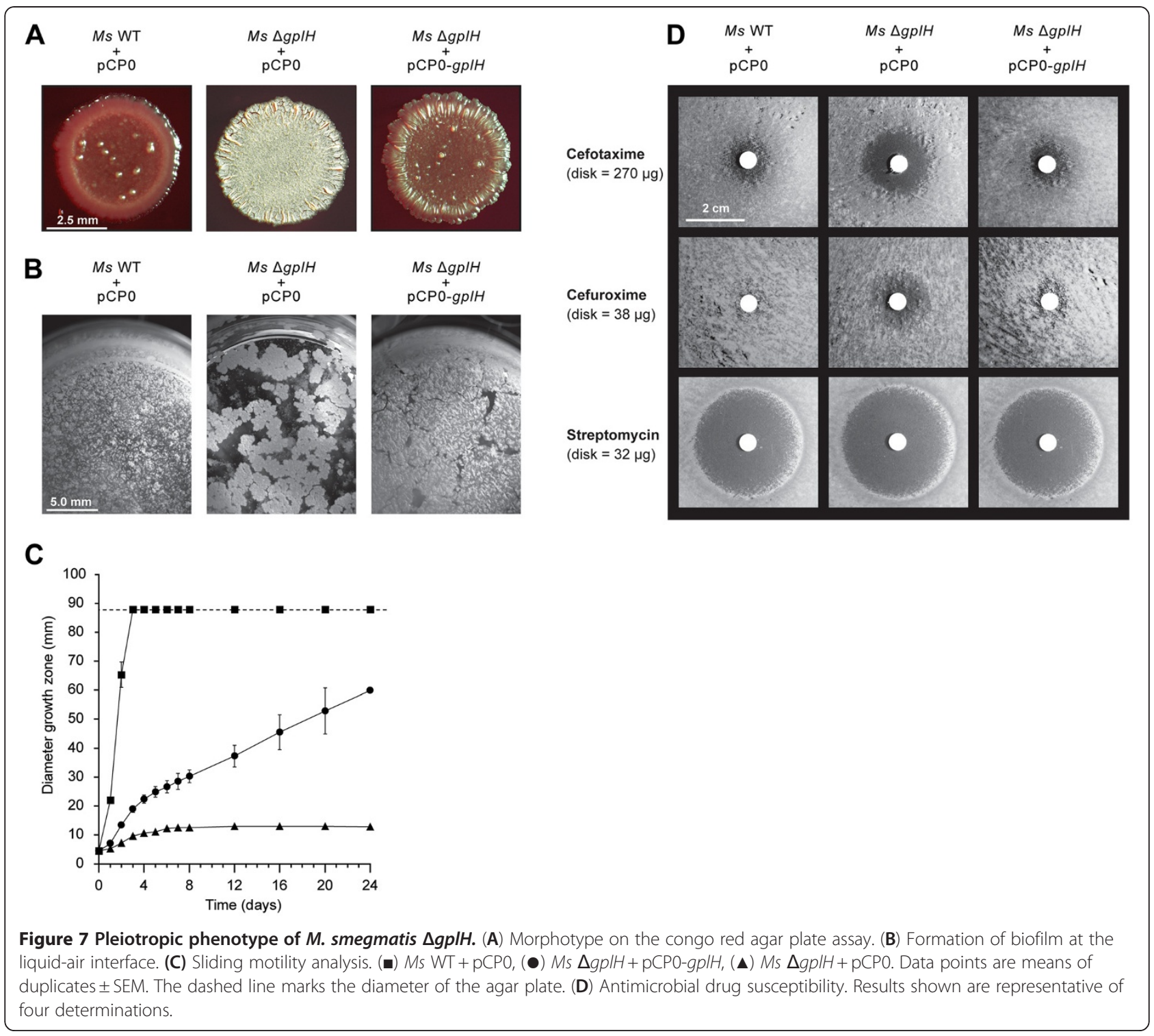

the mutant was complemented by episomal expression of $\mathrm{gplH}$.

The molecular mechanism behind the cephalosporin hypersusceptibility arising from the lack of $g p l H$ remains obscure. It is generally believed that the permeability barrier imposed by the mycobacterial outer membrane reduces antibiotic susceptibility by decreasing compound penetration. Thus, it is tempting to hypothesize that the observed cephalosporin hypersusceptibility arises from an alteration in the permeability barrier of the outer membrane of the $g p l H$ mutant due to the lack of GPLs. The observation that lack of GPLs correlates with a reduction in the permeability barrier to chenodeoxycholate uptake [19] is in line with this hypothesis. The absence of GPLs might produce structural or fluidity changes in the membrane that lead to an increase in cephalosporin penetration. The fact that $M s \quad \Delta g p l H$ displays only a modest increase in antibiotic susceptibility suggests, however, that the lack of GPLs in the outer membrane of the mutant does not have a profound effect on the permeability barrier that this cell envelope structure presents to drug penetration. Thus, our results support the view that GPLs are not critical contributors to the physical integrity of the permeability barrier of the mycobacterial cell envelope.

\section{Conclusions}

Our results unambiguously demonstrate that the conserved gene $g p l H$ is required for GPL production and its inactivation leads to a pleiotropic phenotype. While genes encoding members of the $\mathrm{MbtH}$-like protein family have been shown to be required for production of siderophores or antibiotics [41-44], our findings present the first case of one such gene required for 
biosynthesis of a cell wall component. Furthermore, $g p l H$ is the first $m b t H$-like gene with proven functional role in a member of the Mycobacterium genus. Altogether, this study formally demonstrates a critical role for $g p l H$ in mycobacterial biology and advances our understanding of the genetic requirements for the biosynthesis of an important group of constituents of the unique mycobacterial outer membrane.

\section{Methods}

\section{Culturing conditions and recombinant DNA} manipulations

Ms strain $\mathrm{mc}^{2} 155$ (ATCC 700084) and its derivatives were routinely cultured under standard conditions $\left(37^{\circ} \mathrm{C}\right.$, $225 \mathrm{rpm}$ ) in Middlebrook 7H9 (Difco) supplemented with $10 \% \mathrm{ADN}$ (5\% BSA, 2\% dextrose, $0.85 \% \mathrm{NaCl}$ ), $0.2 \%$ glycerol and $0.05 \%$ Tween-80 (supplemented $7 \mathrm{H} 9$ ) or in Middlebrook 7H11 (Difco) supplemented with 10\% ADN (supplemented 7H11) [55]. E. coli DH5 $\alpha$ (Invitrogen) was cultured under standard conditions in Luria-Bertani media [56]. When required, kanamycin $(30 \mu \mathrm{g} / \mathrm{ml})$, hygromycin $(50 \mu \mathrm{g} / \mathrm{ml})$, sucrose $(2 \%)$ and/or X-gal $(70 \mu \mathrm{g} / \mathrm{ml})$ were added to the media. General recombinant DNA manipulations were carried out by standard methods and using E. coli as the primary cloning host [56]. Molecular biology reagents were obtained from Sigma, Invitrogen, New England Biolabs, Novagen, QIAGEN, or Stratagene. Oligonucleotides were purchased from Integrated DNA Technologies, Inc. PCR-generated DNA fragments used in plasmid constructions were sequenced to verify fidelity. Chromosomal DNA isolation from and plasmid electroporation into mycobacteria were carried out as reported [55]. Table 1 lists the plasmids and oligonucleotide primers used in this study.

\section{Construction of $M$. smegmatis $\Delta g p / H$}

Ms $\triangle g p l H$ was engineered using the p2NIL/pGOAL19based flexible cassette method [57] as previously reported $[4,31,35,58]$. A suicide delivery vector (p2NIL-GOALc$\Delta$ gplHc, see below) carrying a gplH (MSMEG_0399) deletion cassette $(\Delta \mathrm{gplHc})$ was used to generate $M s \Delta g p l H$. The vector was electroporated into $M s$ and transformants with a potential p2NIL-GOALc- $\Delta$ gplHc integration via a single-crossover event (blue colonies) were selected on supplemented 7H11 containing hygromycin, kanamycin, and X-gal. The selected transformants were then grown in antibiotic-free supplemented $7 \mathrm{H} 9$, and subsequently plated for single colonies on supplemented 7H11 containing sucrose and X-gal. White colonies that grew on the sucrose plates were re-streaked onto antibiotic-free and antibiotic-containing supplemented 7H11 plates to identify clones that lost drug resistance, a trait indicating a possible double-crossover event with consequent loss of $g p l H$ or reversion to WT. The deletion of $g p l H$ in antibiotic sensitive clones was screened for and confirmed by PCR. Towards this end, chromosomal DNA isolated from mutant candidates was used as template along with primer pairs (pepOF and pepOR, pepF and pepR) that produced diagnostic amplicons permitting differentiation between the mutant and WT genotypes.

\section{Construction of p2NIL-GOALc- $\Delta$ gplHc and pCPO-gp/H}

The plasmid p2NIL-GOALc- $\Delta$ gplHc used in the construction of $M s \Delta g p l H$ carried the $g p l H$ deletion cassette $\Delta$ gplHc. The deletion cassette contained: 995-bp segment upstream of $g p l H+g p l H$ 's first 13 codons ( $5^{\prime}$ fragment) followed by gplH's last 4 codons + stop codon + 1,000-bp segment downstream of gplH ( $3^{\prime}$ fragment).

Table 1 Plasmids and oligonucleotide primers

\begin{tabular}{|c|c|c|}
\hline Plasmid & Characteristics & Source or Reference \\
\hline pCR2.1-TOPO & Cloning vector, kanamycin resistance and ampicillin resistance genes & Invitrogen \\
\hline $\mathrm{pCPO}$ & Vector for gene expression in mycobacteria, kanamycin resistance gene & [4] \\
\hline pCPO-gp/H & pCPO expressing M. smegmatis gplH & This study \\
\hline pCPO-mbthMs & pCP0 expressing M. smegmatis mbtH (MSMEG_4508) & {$[35]$} \\
\hline $\mathrm{p} 2 \mathrm{NIL}$ & Kanamycin resistance gene and OriE & {$[57]$} \\
\hline pGOAL19 & Hygromycin resistance gene, sacB-lacZ Pacl cassette, and OriE & {$[57]$} \\
\hline p2NIL-GOALc- $\Delta \mathrm{gp} \mid \mathrm{Hc}$ & Delivery vector carrying a $g p / H$ deletion cassette $(\Delta g p \mid H c)$ & This study \\
\hline Oligonucleotide & Sequence $\left(5^{\prime}\right.$ to $\left.3^{\prime}\right)$ & Characteristics \\
\hline pepOF & GGTACCTGTTCAACGCGGCCAGAGCGTCATTGGTCTCGGCCA & Kpnl \\
\hline pepOR & TTAATTAATGTTGCAACAGCTCCCTGATCCGGATGTCGACGTGCTTG & Pad \\
\hline peplR & TCAGCCGTCAAGAGCAAAGCTGCCGTTGTCGTCATCGAACGGGTTGAT & SOE PCR \\
\hline peplF & CGACAACGGCAGCTTTGCTCTTGACGGCTGAGTCAAATAGTCTGTTG & SOE PCR \\
\hline pepF & CTGCAGTGAACAGCCGGGAGAAACGT & Pstl \\
\hline pepR & AAGCTTCCCAACAGACTATTTGACTCAGCCG & Hindlll \\
\hline
\end{tabular}


$\Delta$ gplHc was built by the joining of the $5^{\prime}$ fragment and the 3' fragment using splicing-by-overlap-extension (SOE) PCR [59]. Each fragment was PCR-generated from chromosomal DNA. Primer pair pepOF and pepIR and primer pair pepIF and pepOR were used to generate the 5' and 3' fragments, respectively. The fragments were then used as template for PCR with primers pepOF and pepOR to fuse the fragments and create $\Delta$ gplHc (2,061 bp). The PCR-generated $\triangle \mathrm{gplHc}$ was first cloned into pCR2.1-TOPO (Invitrogen). $\triangle \mathrm{gplHc}$ was subsequently excised from the pCR2.1-TOPO construct using $K p n \mathrm{I}$ and $\mathrm{PacI}$, and the excerpt was ligated to p2NIL [57] linearized by KpnI-PacI digestion. The resulting p2NIL- $\Delta$ gplHc plasmid and plasmid pGOAL19 [57] were digested with PacI, and the PacI cassette (GOALc, $7,939 \mathrm{bp})$ of pGOAL19 was ligated to the linearized p2NIL- $\Delta$ gplHc to create p2NIL-GOALc- $\Delta$ gplHc. To create pCP0-gplH, the plasmid used for complementation analysis, a DNA fragment (266 bp) encompassing $g p l H$ and its predicted ribosome binding site (RBS) was PCR-amplified from genomic DNA with primer pair pepF and pepR and cloned into pCR2.1-TOPO. The RBS-gplH fragment was subsequently excised from the pCR2.1-TOPO construct using PstI and HindIII and ligated to plasmid pCP0 [4] linearized by PstI-HindIII digestion to create pCP0-gplH. The cloning placed gplH under the control of the $h s p 60$ promoter of $\mathrm{pCP0}$ for gene expression in mycobacteria.

\section{Extraction and thin layer chromatography (TLC) analysis of GPLs}

GPLs were extracted and analyzed by TLC by reported methods [22,60]. Cells from cultures $\left(5 \mathrm{ml}, \mathrm{OD}_{600}\right.$ of 1.3-1.6) grown in supplemented $7 \mathrm{H} 9$ as described above were collected by centrifugation $(4,700 \times \mathrm{g}$, $15 \mathrm{~min}$ ), washed with cold phosphate buffered saline (PBS, $1 \mathrm{ml}$ ), and processed for GPL extraction. GPLs were extacted with $2: 1 \mathrm{CHCl}_{3} / \mathrm{CH}_{3} \mathrm{OH}(20 \mu \mathrm{l} / \mathrm{mg}$ wet weight) by incubation overnight at room temperature in a rocking shaker. After incubation, insoluble material was removed by centrifugation $(18,400 \times \mathrm{g}, 10 \mathrm{~min})$, and the $\mathrm{CHCl}_{3} / \mathrm{CH}_{3} \mathrm{OH}$ supernatant was recovered and mixed with 0.2 volumes of $0.9 \% \mathrm{NaCl}$. After vigorous vortexing, the mixture was centrifuged $(1,150 \times \mathrm{g}$, $5 \mathrm{~min}$ ) and the organic phase (containing GPLs) was collected and evaporated to dryness. The dried lipid extracts were dissolved in $20 \mu \mathrm{l}$ of $\mathrm{CHCl}_{3} / \mathrm{CH}_{3} \mathrm{OH}(2: 1)$ and subjected to TLC using aluminum-backed, $250-\mu \mathrm{m}$ silica gel $\mathrm{F}_{254}$ plates developed with $\mathrm{CHCl}_{3} / \mathrm{CH}_{3} \mathrm{OH}$ (100:7). After chromatography, TLC plates were sprayed with orcinol/sulfuric acid $(0.1 \%$ orcinol in $40 \%$ sulfuric acid) and glycolipids were detected by charring at $140^{\circ} \mathrm{C}$.
Preparation and gas chromatography-mass spectrometry (GC-MS) analysis of alditol acetate derivatives

Alditol acetate derivatives of glycosyl units from GPLs were prepared and analyzed as reported [47,61]. Briefly, lipid samples prepared by extraction as noted above were acid-hydrolyzed in $250 \mu \mathrm{l}$ of $2 \mathrm{M}$ trifluoroacetic acid for $2 \mathrm{hr}$ at $120^{\circ} \mathrm{C}$. After cooling down to room temperature, samples were hexane-washed $(250 \mu \mathrm{l})$ and dried on air bath after adding $1 \mu \mathrm{g}$ of 3,6-O-dimethylglucose as an internal standard. The hydrolyzed sugars were reduced overnight at room temperature by adding $250 \mu \mathrm{l}$ of $\mathrm{NaBD}_{4}$ (prepared at $10 \mathrm{mg} / \mathrm{ml}$ in $1 \mathrm{M} \mathrm{NH}_{4} \mathrm{OH}$ in $\left.\mathrm{C}_{2} \mathrm{H}_{5} \mathrm{OH}\right)$. After reduction, glacial acetic acid $(20 \mu \mathrm{l})$ was added to remove excess $\mathrm{NaBD}_{4}$ and the samples were dried. $\mathrm{CH}_{3} \mathrm{OH}(100 \mu \mathrm{l})$ was added to each sample, and after resuspension the solvent was evaporated to dryness (this step was repeated twice). The samples were per- $O$-acetylated with $100 \mu \mathrm{l}$ of acetic anhydride at $120^{\circ} \mathrm{C}$ for $2 \mathrm{hr}$. After cooling, the samples were dried on air bath and suspended in $3 \mathrm{ml}$ of $\mathrm{CHCl}_{3} / \mathrm{H}_{2} \mathrm{O}(2: 1)$ by vortexing. The organic layer was extracted after centrifugation $\left(2,500 \times \mathrm{g}, 5 \mathrm{~min}, 4^{\circ} \mathrm{C}\right)$ and dried on air bath. GC-MS analysis was performed using a Varian CP3800 gas chromatograph (Varian Inc., Palo Alto, CA) equipped with a MS-320 mass spectrometer and using helium gas. The alditol acetate derivatives were dissolved in $50 \mu \mathrm{l}$ of $\mathrm{CHCl}_{3}$ before injection on a DB 5 column (30 $\mathrm{m} \times 0.20 \mathrm{~mm}$ inner diameter) with an initial oven temperature of $50^{\circ} \mathrm{C}$ for $1 \mathrm{~min}$, followed by an increase of $30^{\circ} \mathrm{C} / \mathrm{min}$ to $150^{\circ} \mathrm{C}$ and finally to $275^{\circ} \mathrm{C}$ at $5^{\circ} \mathrm{C} / \mathrm{min}$.

\section{Congo red agar plate assay}

The assay was carried out using reported methodologies [23]. Briefly, mycobacterial cultures $\left(5 \mathrm{ml}, \mathrm{OD}_{600}=1.5\right)$ were shortly vortexed with glass beads to increase homogeneity and then centrifuged $(4,700 \times \mathrm{g}, 15 \mathrm{~min})$ for cell collection. The collected cells were washed with PBS $(5 \mathrm{ml})$ and subsequently resuspended in PBS to an $\mathrm{OD}_{600}$ of 1 . The cell suspensions were spotted $(2 \mu \mathrm{l})$ on congo red agar plates [23] (7H9 basal medium, 1.5\% agar, $100 \mu \mathrm{g} / \mathrm{ml}$ congo red (sodium salt of 3,3'-([1,1'-biphenyl]4,4'-diyl)bis(4-aminonaphthalene-1-sulfonic acid), Sigma Aldrich Co.), $0.02 \%$ glucose, $30 \mu \mathrm{g} / \mathrm{ml}$ kanamycin). Colony morphology was examined using an Olympus SZX7 stereo microscope after plate incubation $\left(37^{\circ} \mathrm{C}, 3\right.$ days).

\section{Sliding motility test}

The test was performed by standard methods [19]. Briefly, mycobacterial cell suspensions in PBS prepared as noted above were spotted $(2 \mu \mathrm{l})$ on sliding motility assay plates [19] (7H9 basal medium, 0.3\% agarose, $30 \mu \mathrm{g} / \mathrm{ml}$ kanamycin). The sliding motility plates were incubated at $37^{\circ} \mathrm{C}$ and the degree of spreading (diameter 
of growth zone) was determined at the time points indicated in results.

\section{Biofilm formation assay}

The liquid-air interface biofilm assay was conducted based on reported methods [53]. Overnight mycobacterial cultures $(5 \mathrm{ml})$ grown in supplemented $7 \mathrm{H} 9$ as noted above were centrifuged $(4,700 \times \mathrm{g}, 15 \mathrm{~min})$ for cell collection. The cells were washed twice with $5 \mathrm{ml}$ of supplemented 7H9 without Tween-80. After washing, the cells were resuspended in supplemented $7 \mathrm{H} 9$ without Tween-80 to a calculated $\mathrm{OD}_{600}$ of 10 . A $25 \mu \mathrm{l}$ aliquot of each suspension was inoculated onto the surface of $2.5 \mathrm{ml}$ of supplemented $7 \mathrm{H} 9$ without Tween-80 loaded into a well of a 12-well polystyrene plate. The plate was incubated for 4 days without shaking at $37^{\circ} \mathrm{C}$ before examination for biofilm formation.

\section{Drug susceptibility assay}

Standard disk-diffusion assays were carried out as reported $[58,62]$. Exponentially growing cultures $\left(\mathrm{OD}_{600}=0.6\right)$ in supplemented $7 \mathrm{H} 9$ were diluted in fresh medium to an $\mathrm{OD}_{600}$ of 0.05 , and $100 \mu \mathrm{l}$ of diluted culture were used to seed $7 \mathrm{H} 11$ plates $(20 \mathrm{ml}$ agar/plate). Antibiotic disks were placed onto the inoculated agar and the plates were incubated at $37^{\circ} \mathrm{C}$ for 2 days before analysis. The antibiotics tested were doxycycline, isoniazid, streptomycin, tetracycline, cefuroxime, erythromycin, ciprofloxacin, levofloxacin, ethambutol, ethionamide, rifampicin, clarithromycin, cefuroxime, cephalexin, and cefotaxime. The antibiotics were acquired from Sigma-Aldrich, Fisher Scientific, Tokyo Chemical Industry, or Calbiochem Biochemicals.

\section{Abbreviations \\ GC-MS: Gas chromatography-mass spectrometry; GPL: Glycopeptidolipid; MAC: Mycobacterium avium-Mycobacterium intracellulare complex; Ms: Mycobacterium smegmatis; NRPS: Nonribosomal peptide synthetase; PBS: Phosphate buffered saline; PKS: Polyketide synthetase; TLC: Thin layer chromatography.}

\section{Competing interests}

The authors declare that they have no competing interests.

\section{Authors' contributions}

LQ conceived the study. ET, SC, PM, UE and SA carried out the experiments. $L Q, E T, S C$, and DC analyzed results and drafted the manuscript. All authors read and approved the final manuscript.

\section{Acknowledgements}

This work was supported by NIH Grant R01Al075092 to LQ and NIH Grant RO1 Al37139 to DC. LQ acknowledges the endowment support from Carol and Larry Zicklin.

\section{Author details}

${ }^{1}$ Department of Biology, Brooklyn College, City University of New York, 2900 Bedford Avenue, Brooklyn, NY 11210, USA. ²Department of Microbiology, Immunology and Pathology, College of Veterinary Medicine and Biomedical Sciences, Colorado State University, 1682 Campus Delivery, Fort Collins, CO 80523, USA.
Received: 11 January 2012 Accepted: 7 May 2012

Published: 22 June 2012

\section{References}

1. Brennan PJ, Nikaido H: The envelope of mycobacteria. Annu Rev Biochem 1995, 64:29-63.

2. Crick DC, Quadri LE, Brennan PJ: Biochemistry of the cell envelope of Mycobacterium tuberculosis. In Handbook of Tuberculosis: Molecular Biology and Biochemistry. Edited by Kaufmann SHE, Weinheim RR. KgaA: WILEY-VCH Verlag GmbH \& Co; 2008:1-20.

3. Onwueme KC, Vos CJ, Zurita J, Ferreras JA, Quadri LE: The dimycocerosate ester polyketide virulence factors of mycobacteria. Prog Lipid Res 2005, 44:259-302.

4. Ferreras JA, Stirrett KL, Lu X, Ryu JS, Soll CE, Tan DS, Quadri LE: Mycobacterial phenolic glycolipid virulence factor biosynthesis: mechanism and small-molecule inhibition of polyketide chain initiation. Chem Biol 2008, 15:51-61.

5. Ferreras JA, Ryu JS, Di Lello F, Tan DS, Quadri LE: Small-molecule inhibition of siderophore biosynthesis in Mycobacterium tuberculosis and Yersinia pestis. Nat Chem Biol 2005, 1:29-32.

6. Quadri LEN: Strategic paradigm shifts in the antimicrobial drug discovery process of the $21^{\text {st }}$ century. Infect Disord Drug Targets 2007, 7:230-237.

7. Chatterjee $\mathrm{D}$, Khoo KH: The surface glycopeptidolipids of mycobacteria: structures and biological properties. Cell Mol Life Sci 2001, 58:2018-2042.

8. Schorey JS, Sweet L: The mycobacterial glycopeptidolipids: structure, function, and their role in pathogenesis. Glycobiology 2008, 18:832-841.

9. Field SK, Fisher D, Cowie RL: Mycobacterium avium complex pulmonary disease in patients without HIV infection. Chest 2004, 126:566-581.

10. Marras TK, Daley CL: Epidemiology of human pulmonary infection with nontuberculous mycobacteria. Clin Chest Med 2002, 23:553-567.

11. Rhoades ER, Archambault AS, Greendyke R, Hsu FF, Streeter C, Byrd TF: Mycobacterium abscessus Glycopeptidolipids mask underlying cell wall phosphatidyl-myo-inositol mannosides blocking induction of human macrophage TNF-alpha by preventing interaction with TLR2. J Immunol 2009, 183:1997-2007.

12. Shimada K, Takimoto H, Yano I, Kumazawa Y: Involvement of mannose receptor in glycopeptidolipid-mediated inhibition of phagosomelysosome fusion. Microbiol Immunol 2006, 50:243-251.

13. Kano H, Doi T, Fujita Y, Takimoto H, Yano I, Kumazawa Y: Serotype-specific modulation of human monocyte functions by glycopeptidolipid (GPL) isolated from Mycobacterium avium complex. Biol Pharm Bull 2005, 28:335-339.

14. Villeneuve C, Etienne G, Abadie V, Montrozier H, Bordier C, Laval F, Daffe M, Maridonneau-Parini I, Astarie-Dequeker C: Surface-exposed glycopeptidolipids of Mycobacterium smegmatis specifically inhibit the phagocytosis of mycobacteria by human macrophages. Identification of a novel family of glycopeptidolipids. J Biol Chem 2003, 278:51291-51300.

15. Villeneuve C, Gilleron M, Maridonneau-Parini I, Daffe M, Astarie-Dequeker C, Etienne G: Mycobacteria use their surface-exposed glycolipids to infect human macrophages through a receptor-dependent process. $J$ Lipid Res 2005, 46:475-483.

16. Barrow WW, Davis TL, Wright EL, Labrousse V, Bachelet M, Rastogi N: Immunomodulatory spectrum of lipids associated with Mycobacterium avium serovar 8. Infect Immun 1995, 63:126-133.

17. Sweet L, Singh PP, Azad AK, Rajaram MV, Schlesinger LS, Schorey JS: Mannose receptor-dependent delay in phagosome maturation by Mycobacterium avium glycopeptidolipids. Infect Immun 2010, 78:518-526.

18. Recht J, Martinez A, Torello S, Kolter R: Genetic analysis of sliding motility in Mycobacterium smegmatis. J Bacteriol 2000, 182:4348-4351.

19. Etienne G, Villeneuve C, Billman-Jacobe $H$, Astarie-Dequeker C, Dupont MA, Daffe M: The impact of the absence of glycopeptidolipids on the ultrastructure, cell surface and cell wall properties, and phagocytosis of Mycobacterium smegmatis. Microbiology 2002, 148:3089-3100.

20. Kocincova D, Singh AK, Beretti IL, Ren H, Euphrasie D, Liu J, Daffe M, Etienne G, Reyrat JM: Spontaneous transposition of IS1096 or ISMsm3 leads to glycopeptidolipid overproduction and affects surface properties in Mycobacterium smegmatis. Tuberculosis (Edinb) 2008, 88:390-398. 
21. Khoo KH, Jarboe E, Barker A, Torrelles J, Kuo CW, Chatterjee D: Altered expression profile of the surface glycopeptidolipids in drug-resistant clinical isolates of Mycobacterium avium complex. J Biol Chem 1999, 274:9778-9785.

22. Billman-Jacobe H, McConville MJ, Haites RE, Kovacevic S, Coppel RL: Identification of a peptide synthetase involved in the biosynthesis of glycopeptidolipids of Mycobacterium smegmatis. Mol Microbiol 1999, 33:1244-1253.

23. Sonden B, Kocincova D, Deshayes C, Euphrasie D, Rhayat L, Laval F, Frehel C, Daffe M, Etienne G, Reyrat JM: Gap, a mycobacterial specific integral membrane protein, is required for glycolipid transport to the cell surface. Mol Microbiol 2005, 58:426-440.

24. Ripoll F, Deshayes C, Pasek S, Laval F, Beretti JL, Biet F, Risler JL, Daffe M, Etienne G, Gaillard JL, Reyrat JM: Genomics of glycopeptidolipid biosynthesis in Mycobacterium abscessus and M. chelonae. BMC Genomics 2007, 8:114.

25. Chen J, Kriakov J, Singh A, Jacobs WR Jr, Besra GS, Bhatt A: Defects in glycopeptidolipid biosynthesis confer phage 13 resistance in Mycobacterium smegmatis. Microbiology 2009, 155:4050-4057.

26. Walsh $C T$ : Polyketide and nonribosomal peptide antibiotics: modularity and versatility. Science 2004, 303:1805-1810.

27. Fischbach MA, Walsh CT: Assembly-line enzymology for polyketide and nonribosomal Peptide antibiotics: logic, machinery, and mechanisms. Chem Rev 2006, 106:3468-3496.

28. Crosa JH, Walsh CT: Genetics and assembly line enzymology of siderophore biosynthesis in bacteria. Microbiol Mol Biol Rev 2002, 66:223-249

29. Quadri LE: Assembly of aryl-capped siderophores by modular peptide synthetases and polyketide synthases. Mol Microbiol 2000, 37:1-12.

30. Buglino J, Onwueme KC, Ferreras JA, Quadri LE, Lima CD: Crystal structure of PapA5, a phthiocerol dimycocerosyl transferase from Mycobacterium tuberculosis. J Biol Chem 2004, 279:30634-30642.

31. Onwueme KC, Ferreras JA, Buglino J, Lima CD, Quadri LE: Mycobacterial polyketide-associated proteins are acyltransferases: Poof of principle with Mycobacterium tuberculosis PapA5. Proc Natl Acad Sci USA 2004, 101:4608-4613.

32. Deshayes C, Laval F, Montrozier H, Daffe M, Etienne G, Reyrat JM: A glycosyltransferase involved in biosynthesis of triglycosylated glycopeptidolipids in Mycobacterium smegmatis: impact on surface properties. J Bacteriol 2005, 187:7283-7291.

33. Quadri LE, Sello J, Keating TA, Weinreb PH, Walsh CT: Identification of a Mycobacterium tuberculosis gene cluster encoding the biosynthetic enzymes for assembly of the virulence-conferring siderophore mycobactin. Chem Biol 1998, 5:631-645.

34. Baltz RH: Function of MbtH homologs in nonribosomal peptide biosynthesis and applications in secondary metabolite discovery. $J$ Ind Microbiol Biotechnol 2011, 38:1747-1760.

35. Chavadi SS, Stirrett KL, Edupuganti UR, Sadhanandan G, Vergnolle O, Schumacher E, Martin C, Qiu WG, Soll CE, Quadri LEN: Mutational and phylogenetic analyses of the mycobacterial mbt gene cluster. $J$ Bacterio 2011, 193:5905-5913.

36. Heemstra JR Jr, Walsh CT, Sattely ES: Enzymatic tailoring of ornithine in the biosynthesis of the Rhizobium cyclic trihydroxamate siderophore vicibactin. J Am Chem Soc 2009, 131:15317-15329.

37. Imker HJ, Krahn D, Clerc J, Kaiser M, Walsh CT: N-acylation during glidobactin biosynthesis by the tridomain nonribosomal peptide synthetase module GlbF. Chem Biol 2010, 17:1077-1083.

38. Felnagle EA, Barkei JJ, Park H, Podevels AM, McMahon MD, Drott DW, Thomas MG: MbtH-like proteins as integral components of bacterial nonribosomal peptide synthetases. Biochemistry 2010, 49:8815-8817.

39. Zhang W, Heemstra JR Jr, Walsh CT, Imker HJ: Activation of the pacidamycin PacL adenylation domain by $\mathrm{MbtH}$-like proteins. Biochemistry 2010, 49:9946-9947.

40. Boll B, Taubitz T, Heide L: Role of MbtH-like proteins in the adenylation of tyrosine during aminocoumarin and vancomycin biosynthesis. $J$ Biol Chem 2011, 286:36281-36290.

41. Lautru S, Oves-Costales D, Pernodet JL, Challis GL: MbtH-like proteinmediated cross-talk between non-ribosomal peptide antibiotic and siderophore biosynthetic pathways in Streptomyces coelicolor M145. Microbiology 2007, 153:1405-1412.

42. Drake EJ, Cao J, Qu J, Shah MB, Straubinger RM, Gulick AM: The $1.8 \AA$ crystal structure of PA2412, an MbtH-like protein from the pyoverdine cluster of Pseudomonas aeruginosa. J Biol Chem 2007, 282:20425-20434

43. Carter RA, Worsley PS, Sawers G, Challis GL, Dilworth MJ, Carson KC, Lawrence JA, Wexler M, Johnston AW, Yeoman KH: The vbs genes that direct synthesis of the siderophore vicibactin in Rhizobium leguminosarum: their expression in other genera requires ECF sigma factor Rpol. Mol Microbiol 2002, 44:1153-1166.

44. Wolpert M, Gust B, Kammerer B, Heide L: Effects of deletions of mbtH-like genes on clorobiocin biosynthesis in Streptomyces coelicolor. Microbiology 2007, 153:1413-1423.

45. Stegmann E, Rausch C, Stockert S, Burkert D, Wohlleben W: The small $\mathrm{MbtH}$-like protein encoded by an internal gene of the balhimycin biosynthetic gene cluster is not required for glycopeptide production. FEMS Microbiol Lett 2006, 262:85-92.

46. Biet F, Bay S, Thibault VC, Euphrasie D, Grayon M, Ganneau C, Lanotte P, Daffe M, Gokhale R, Etienne G, Reyrat JM: Lipopentapeptide induces a strong host humoral response and distinguishes Mycobacterium avium subsp. paratuberculosis from M. avium subsp. avium. Vaccine 2008, 26:257-268

47. McNeil M, Chatterjee D, Hunter SW, Brennan PJ: Mycobacterial glycolipids: isolation, structures, antigenicity, and synthesis of neoantigens. Methods Enzymol 1989, 179:215-242.

48. Fiss EH, Yu S, Jacobs WR Jr: Identification of genes involved in the sequestration of iron in mycobacteria: the ferric exochelin biosynthetic and uptake pathways. Mol Microbiol 1994, 14:557-569.

49. Yu S, Fiss E, Jacobs WR Jr: Analysis of the exochelin locus in Mycobacterium smegmatis: biosynthesis genes have homology with genes of the peptide synthetase family. J Bacteriol 1998, 180:4676-4685.

50. Zhu W, Arceneaux JE, Beggs ML, Byers BR, Eisenach KD, Lundrigan MD: Exochelin genes in Mycobacterium smegmatis: identification of an $A B C$ transporter and two non-ribosomal peptide synthetase genes. Mol Microbiol 1998, 29:629-639.

51. Quadri LEN, Ratledge C: Iron metabolism in the tubercle bacillus and other mycobacteria. In Tuberculosis and the Tubercle Bacillus. Edited by Cole ST, Eisenach KD, McMurray DN, Jacobs WRJ. Washington, DC: ASM Press; 2005:341-357.

52. Rodriguez GM, Smith I: Mechanisms of iron regulation in mycobacteria: role in physiology and virulence. Mol Microbiol 2003, 47:1485-1494.

53. Ojha A, Hatfull GF: The role of iron in Mycobacterium smegmatis biofilm formation: the exochelin siderophore is essential in limiting iron conditions for biofilm formation but not for planktonic growth. $\mathrm{Mol}$ Microbiol 2007, 66:468-483.

54. Ojha A, Anand M, Bhatt A, Kremer L, Jacobs WR Jr, Hatfull GF: GroEL1: a dedicated chaperone involved in mycolic acid biosynthesis during biofilm formation in mycobacteria. Cell 2005, 123:861-873.

55. In Mycobacteria protocols. Edited by Parish T, Stoker NG. Totowa, New Jersey: Humana Press; 1998.

56. Sambrook J, Russell DW: Molecular cloning: A laboratory manual. Third Editionth edition. Cold Spring Harbor, NY: Cold Spring Harbor Laboratory Press; 2001.

57. Parish T, Stoker NG: Use of a flexible cassette method to generate a double unmarked Mycobacterium tuberculosis tlyA plcABC mutant by gene replacement. Microbiology 2000, 146:1969-1975.

58. Chavadi SS, Edupuganti UR, Vergnolle O, Fatima I, Singh SM, Soll CE, Quadri LE: Inactivation of tesA reduces cell wall lipid production and increases drug susceptibility in mycobacteria. J Biol Chem 2011, 286:24616-24625.

59. Horton RM, Hunt HD, Ho SN, Pullen JK, Pease LR: Engineering hybrid genes without the use of restriction enzymes: gene splicing by overlap extension. Gene 1989, 77:61-68.

60. Folch J, Lees M, Sloane Stanley GH: A simple method for the isolation and purification of total lipides from animal tissues. J Biol Chem 1957, 226:497-509. 
61. Eckstein TM, Silbaq FS, Chatterjee D, Kelly NJ, Brennan PJ, Belisle JT: Identification and recombinant expression of a Mycobacterium avium rhamnosyltransferase gene (rtfA) involved in glycopeptidolipid biosynthesis. J Bacteriol 1998, 180:5567-5573.

62. Palma M, Zurita J, Ferreras JA, Worgall S, Larone DH, Shi L, Campagne F, Quadri LE: Pseudomonas aeruginosa SoxR does not conform to the archetypal paradigm for SoxR-dependent regulation of the bacterial oxidative stress adaptive response. Infect Immun 2005, 73:2958-2966.

doi:10.1186/1471-2180-12-118

Cite this article as: Tatham et al:: Production of mycobacterial cell wall glycopeptidolipids requires a member of the MbtH-like protein family. BMC Microbiology 2012 12:118.

\section{Submit your next manuscript to BioMed Central and take full advantage of:}

- Convenient online submission

- Thorough peer review

- No space constraints or color figure charges

- Immediate publication on acceptance

- Inclusion in PubMed, CAS, Scopus and Google Scholar

- Research which is freely available for redistribution 